\title{
Estudo do perfil de textura, mobilidade de água e evolução de diacetil em queijo Prato tradicional e light
}

\author{
Giovanna L. Z. Camargo (IC), Lígia D. Domingos (PG), Walkíria H. Viotto (PQ)
}

\section{Resumo}

A redução de gordura e a adição de CPS mudam a composição, mobilidade de água e a microestrutura do queijo, o que pode afetar a ação das enzimas durante a cura do queijo. Essas mudanças podem afetar a produção de diacetil, composto volátil responsável pelo aroma típico de manteiga em queijo Prato. O objetivo do trabalho foi estudar as mudanças causadas redução de gordura e adição de CPS na mobilidade de água, evolução de diacetil e perfil de textura durante o tempo de maturação (210 dias) do queijo Prato. Queijo Prato integral, com redução de gordura (light) e light com adição de CPS foram fabricados em duplicata. Os queijos foram armazenados por 210 dias, a $8^{\circ} \mathrm{C}$, e análises de mobilidadade de água, teor de diacetil e perfil de textura foram realizadas durante esse período. A redução de gordura e a adição de CPS resultaram em queijos com boas características de textura, teores mais elevados de diacetil no início da maturação e poucas mudanças na mobilidade de água.

\section{Palavras Chave: redução de gordura, concentrado protéico de soro, maturação}

\section{Introdução}

A maior preocupação do consumidor com a saúde e estética tem aumentado a demanda por produtos com teor de gordura reduzido. Entre eles estão os queijos, como o tipo Prato, terceiro mais consumido no Brasil. No entanto, a remoção da gordura pode causar defeitos resultantes de alterações na mobilidade de água, como baixa produção de compostos voláteis, textura dura e elástica e propriedades funcionais diferentes. Para corrigir $\mathrm{o}$ defeito da textura, muitas indústrias adicionam CPS como mimetico de gordura, já que ele apresenta boa capacidade de retenção de água ${ }^{1}$.A redução de gordura e a adição de CPS mudam a composição, mobilidade de água e a microestrutura do queijo, o que pode afetar a ação das enzimas durante a cura do queijo. Essas mudanças podem afetar a produção de diacetil, composto volátil responsável pelo aroma típico de manteiga em queijo Prato.

O objetivo do trabalho foi estudar as mudanças causadas pela redução de gordura e adição de CPS na mobilidade de água, evolução de diacetil e perfil de textura durante o tempo de maturação (210 dias) do queijo Prato.

\section{Resultados e Discussão}

A redução de gordura resultou em queijos com maiores teores de água imobilizada e ligada e menores de água livre. Para todos os queijos, as populações de água ligada diminuíram ao longo do tempo.A redução de gordura e a adição de CPS provocaram um aumento do teor de diacetil no início da maturação dos queijos. Essa é uma característica altamente desejável, já que o diacetil é um composto associado ao sabor do queijo Prato. A adição de CPS melhorou a textura com a diminuição dos valores de coesividade, mastigabilidade e elasticidade.

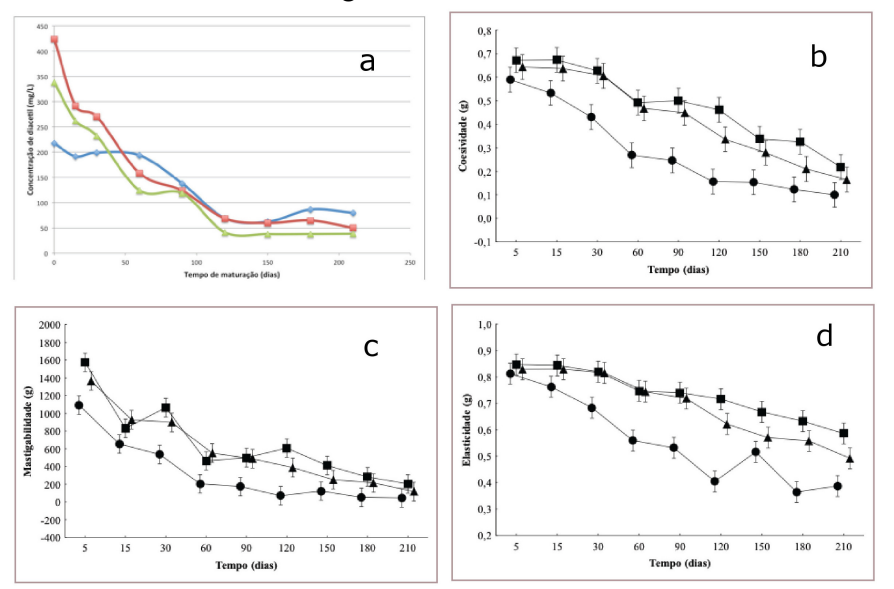

Figura 1. Evolução do teor de diacetil (a), coesividade (b), mastigabilidade (c), elasticidade (d) com o tempo de maturação do queijo Prato. $(\bullet \bullet)$ integral, (घ匹) light, ( $\Delta \mathbf{\Delta})$ light com CPS.

\section{Conclusões}

A redução de gordura e a adição de CPS resultaram em queijos com boas características de textura, teores mais elevados de diacetil no início da maturação e poucas mudanças na mobilidade de água.

\section{Agradecimentos}

Ao PIBIC/CNPQ, pela oportunidade de desenvolver esse projeto.

${ }^{1}$ DRAKE, M. A.; MIRACLE, R. E.; MCMAHON, D. J. Impact of fat reduction on flavor and flavor chemistry of Cheddar cheeses. JournalofDairy Science, v. 93; $5069-5081,2010$. 